\title{
Is less really more? Endoscopic mucosal resection versus esophagectomy for submucosal esophageal adenocarcinoma
}

\author{
Siva Raja, MD, PhD, ${ }^{a}$ Alejandro C. Bribriesco, MD, ${ }^{a}$ and Madhu R. Sanaka, MD ${ }^{b}$ \\ From the ${ }^{\mathrm{a}}$ Department of Thoracic and Cardiovascular Surgery, Heart and Vascular Institute, and ${ }^{\mathrm{b}}$ Department of \\ Gastroenterology and Hepatology, Digestive Disease and Surgery Institute, Cleveland Clinic, Cleveland, Ohio. \\ Disclosures: Authors have nothing to disclose with regard to commercial support. \\ Received for publication March 7, 2018; accepted for publication March 9, 2018; available ahead of print April \\ $13,2018$. \\ Address for reprints: Siva Raja, MD, PhD, Department of Thoracic and Cardiovascular Surgery, Cleveland Clinic, \\ 9500 Euclid Ave, Desk J4-133, Cleveland, OH 44195 (E-mail: rajas@ccf.org). \\ J Thorac Cardiovasc Surg 2018;156:414-5 \\ $0022-5223 / \$ 36.00$ \\ Copyright $(c) 2018$ by The American Association for Thoracic Surgery \\ https://doi.org/10.1016/j.jtcvs.2018.03.030
}

The advent of minimally invasive surgery during the past several decades has challenged and changed the old dictums of surgical practice. It showed us that minimally invasive surgery can be performed with less of an incision, less trauma to tissues and patients, and less recovery time, and truly with more value to the patient. In the same way that laparoscopic surgery challenged open surgery, endoscopic surgery is challenging laparoscopic surgery-small incisions versus no incisions.

In their report in this issue of the Journal, Nelson and colleagues ${ }^{1}$ examine the value of endoscopic mucosal resection (EMR) for submucosal adenocarcinoma relative to the traditional surgical therapy, esophagectomy. In their retrospective study from a prospective database, Nelson and colleagues ${ }^{1}$ found that local recurrence was higher in the EMR group, whereas the rate of distant recurrence was not significantly different. With propensity matching, there was no significant difference, likely as a result of small numbers $(n=15$ in each arm). In the study of Nelson and colleagues, ${ }^{1}$ EMR was less frequently performed on deeper and high-risk lesions. Despite the selection bias, there is valuable information to be garnered. The scoring system proposed by Nelson and colleagues $^{1}$ to identify low-risk lesions can help one to decide whether to perform EMR instead of esophagectomy when both options are on the table.

Even as you read this editorial, EMR is quickly being supplanted by endoscopic submucosal dissection. Endoscopic submucosal dissection has the potential to be superior to EMR, in that it allows resection of larger lesions en bloc rather than piecemeal, and it allows the resection of both mucosal and submucosal layers. As such, the potential for complete resection is higher, with potentially lower local recurrence. Although only time and rigorous study will tell whether endoscopic submucosal dissection is superior to EMR for therapeutic intent, there is less doubt with regard to their diagnostic value. The accuracy of identifying less.

\section{References}

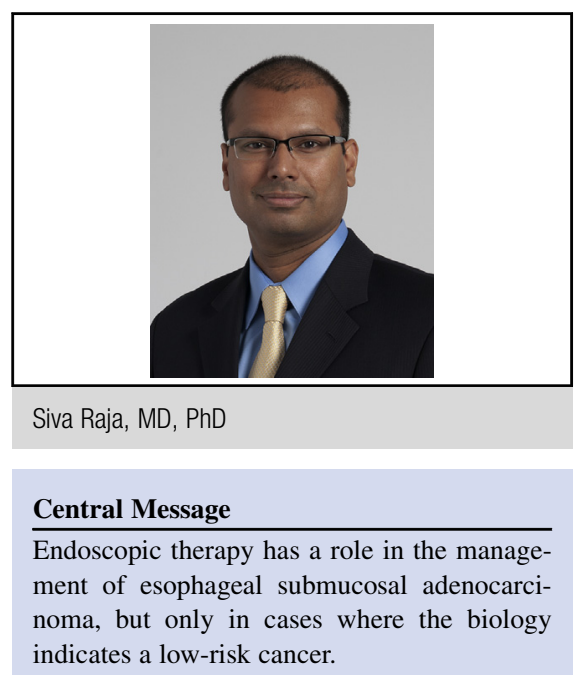

See Article page 406

cT1a versus cT1b with endoscopic ultrasound is limited, let alone the distinctions among SM1, SM2 and SM3. ${ }^{2,3}$ As such, there is likely a role for endoscopic resection for the purpose of accurately staging superficial cancers.

Although mechanical limitations can be overcome by advances in surgical technique, patient selection and understanding of biology are the ultimate determinants of oncologic success in this subset of patients with cancer. We and others have shown that submucosal cancers of the esophagus can be characterized as superficial cancers but should not be expected to behave like early cancers. ${ }^{4,5}$ The invasion of the tumor within the deep submucosa (SM3) and lymphovascular invasion are significant risk factors for lymph node metastasis. Given that endoscopic therapy does not address locoregional disease, it should not be considered as the only therapy for the treatment of submucosal cancers unless there are mitigating factors, such as poor patient functional status.

In a modern minimally invasive surgical practice, less is usually more. In the endoscopic treatment of submucosal esophageal cancer, however, less can sometimes just be

1. Nelson DB, Dhupar R, Katkhuda R, Correa A, Goltsov A, Maru D, et al. Outcomes after endoscopic mucosal resection or esophagectomy for submucosal esophageal adenocarcinoma. J Thorac Cardiovasc Surg. 2018;156:406-13. 
2. Rampado S, Bocus P, Battaglia G, Ruol A, Portale G, Ancona E. Endoscopic ultrasound: accuracy in staging superficial carcinomas of the esophagus. Ann Thorac Surg. 2008;85:251-6.

3. Luu C, Amaral M, Klapman J, Harris C, Almhanna K, Hoffe S, et al Endoscopic ultrasound staging for early esophageal cancer: are we denying patients neoadjuvant chemo-radiation? World J Gastroenterol. 2017;23: 8193-9.
4. Raja S, Rice TW, Goldblum JR, Rybicki LA, Murthy SC, Mason DP, et al. Esophageal submucosa: the watershed for esophageal cancer. J Thorac Cardiovasc Surg. 2011;142:1403-11.e1.

5. Manner H, Wetzka J, May A, Pauthner M, Pech O, Fisseler-Eckhoff A, et al. Earlystage adenocarcinoma of the esophagus with mid to deep submucosal invasion (pT1b sm2-3): the frequency of lymph-node metastasis depends on macroscopic and histological risk patterns. Dis Esophagus. 2017;30:1-11. 